\title{
Influence of Rotating Speed on the Coupled Bending and Torsional Vibrations of Turbo- Generator Unit with Rub-Impact
}

\author{
http://dx.doi.org/10.3991/ijoe.v9iS2.2565 \\ He Chengbing ${ }^{1}$, Yang $\mathrm{Li}^{2}$ \\ ${ }^{1}$ North China Electric Power University, Beijing, China \\ ${ }^{2}$ China Coal Research Institute, Beijing, China
}

\begin{abstract}
Rub-impact fault causes complicated vibration to the rotor system and is one of the main reasons for the system instability. The increment transfer matrix method is used to analyze the dynamic response of the coupled bending and torsional vibrations of turbo-generator shafts with rub-impact in this work. Aimed at a turbo-generator unit with different rotating speed, the vibration character of rub-impact fault is analyzed. The research results show that the influence of rotating speed on vibration amplitude is obvious. When the speed is lower than the first order inherent frequency, rubbing will cause bending and torsional vibration amplitudes of each shaft segment increase largely. When the speed is higher than the first order inherent frequency, vibration amplitudes slightly change by rubbing. The sensitive to rubbing position is different for increased vibration amplitude of each shaft segment. The shaft segment is more near to the rubbing position, the increased vibration amplitude is more obvious.
\end{abstract}

Index Terms-rub-impact fault, coupled bending and torsional vibrations, increment transfer matrix method, rotating speed, turbo-generator unit.

\section{INTRODUCTION}

With the development of technology, the demand for performance of rotating machinery is becoming greater, the radial gap of rotor to stator smaller, this has led to the frequent occurrence of the rotor-to-stator rub, especially between the rotor and seal or the blade tip and the envelope. It will cause very complicated vibration to the rotor system and is one of the main reasons for the system instability. The behavior of the bending vibration of a rotor with rub-impact has been studied throughly [1-6]. However, it can be known from the rotor dynamic equations that the torsional vibration is as an important part as the vibration. In particular, for a turbo-generation machine, operating at high speed, the coupled bending and torsional vibrations characteristics may be considerably different from those obtained by uncoupled independent analyses. To achieve a highly reliable operation that

\section{(1) The rigid disk}

The shear force and bending moment on the crosssection of the rigid disk are separately $Q^{L}, Q^{R}$ and $M^{L}, M^{R}$. According to D'Alembert principle, the increment equations of shear force and bending moment are obtained as: includes low vibration and noise characteristics, an investigation of the coupled bending and torsional vibrations phenomenon would be desirable. And the research on the behavior of the torsional vibration of a rotor/stator system with rub is very significant for diagnosing rotating machinery. In general the study on coupled vibrations of rubimapct is in the early stages. Simple disc rotor model is adopted widely, that can not really be used to analyze complex rotor system like a turbo-generator unit[7-10].

\section{THE InCREMENT TRANSFER MATRIX METHOD FOR COUPLED VIBRATIONS}

Coupled bending and torsional vibrations exhibit a complex nonlinear dynamic characteristic. The most effective method to solve nonlinear system response is step-by-step integration method. The increment transfer matrix method was put forward in paper[1]. So the method is introduced as follows simply.

\section{A. The Increment Expressions of Newmark- $\beta$ Method}

According to Newmark- $\beta$ method, if the displacment $q_{t}$, velocity $\dot{q}_{t}$ and acceleration $\ddot{q}_{t}$ at $t$ time and displacment $q_{t+\Delta t}$ at $t+\Delta t$ time are known, the velocity $\dot{q}_{t+\Delta t}$ and acceleration $\ddot{q}_{t+\Delta t}$ at $t+\Delta t$ time can be calculated. The increment equations of Newmark- $\beta$ expressions are written as:

$$
\begin{aligned}
& \Delta \ddot{q}_{t}=\ddot{q}(t+\Delta t)-\ddot{q}(t)=\frac{1}{\beta \Delta t^{2}} \Delta q(t)-\frac{1}{\beta \Delta t} \dot{q}(t)-\frac{1}{2 \beta} \ddot{q}(t) \\
& \Delta \dot{q}_{t}=\dot{q}(t+\Delta t)-\dot{q}(t)=\frac{\gamma}{\beta \Delta t} \Delta q(t)-\frac{\gamma}{\beta} \dot{q}(t)-\left(\frac{\gamma}{2 \beta}-1\right) \ddot{q}(t) \Delta t
\end{aligned}
$$

\section{B. The Increment Transfer Matrix Expressions of} Coupled Vibrations

\section{1) The expressions of bending vibration}

Adopting the multi-mass model, the rotor system of turbo-generator unit is divided into several rigid disks and elastic shafts.

$$
\begin{aligned}
& \left\{\begin{array}{c}
\Delta Q_{x} \\
\Delta Q_{y}
\end{array}\right\}_{i}^{\mathrm{R}}=\left\{\begin{array}{l}
\Delta Q_{x} \\
\Delta Q_{y}
\end{array}\right\}_{i}^{\mathrm{L}}+\left[\begin{array}{ll}
A_{11} & A_{12} \\
A_{21} & A_{22}
\end{array}\right]\left\{\begin{array}{l}
\Delta x \\
\Delta y
\end{array}\right\}_{i} \\
& +\left\{\begin{array}{l}
A_{13} \\
A_{23}
\end{array}\right\} \Delta \phi+\left\{\begin{array}{l}
A_{2} \\
B_{2}
\end{array}\right\}
\end{aligned}
$$




$$
\begin{aligned}
& \left\{\begin{array}{l}
\Delta M_{x} \\
\Delta M_{y}
\end{array}\right\}_{i}^{R}=\left\{\begin{array}{l}
\Delta M_{x} \\
\Delta M_{y}
\end{array}\right\}_{i}^{L}+\left[\begin{array}{ll}
A_{31} & A_{32} \\
A_{41} & A_{42}
\end{array}\right]\left\{\begin{array}{l}
\Delta \alpha_{x} \\
\Delta \alpha_{y}
\end{array}\right\}+\left\{\begin{array}{l}
A_{3} \\
B_{3}
\end{array}\right\} \\
& \left\{\begin{array}{l}
\Delta x \\
\Delta y
\end{array}\right\}_{i}^{R}=\left\{\begin{array}{l}
\Delta x \\
\Delta y
\end{array}\right\}_{i}^{L} \quad\left\{\begin{array}{l}
\Delta \alpha_{x} \\
\Delta \alpha_{y}
\end{array}\right\}_{i}^{R}=\left\{\begin{array}{l}
\Delta \alpha_{x} \\
\Delta \alpha_{y}
\end{array}\right\}_{i}^{L}
\end{aligned}
$$

\section{(2) The elastic shaft}

The elastic shaft number is set to $i$. And the numbers of both ends of the cross-section are separately $i$ and $i+1$. The increment equations of the ith elastic shaft can be obtained as follows:

$$
\begin{aligned}
& \left\{\begin{array}{l}
\Delta Q_{x} \\
\Delta Q_{y}
\end{array}\right\}_{i+1}^{L}=\left\{\begin{array}{l}
\Delta Q_{x} \\
\Delta Q_{y}
\end{array}\right\}_{i}^{R} \\
& \left\{\begin{array}{l}
\Delta M_{x} \\
\Delta M_{y}
\end{array}\right\}_{i+1}^{L}=\left\{\begin{array}{l}
\Delta M_{x} \\
\Delta M_{y}
\end{array}\right\}_{i}^{R}+L_{i}\left\{\begin{array}{l}
\Delta Q_{x} \\
\Delta Q_{y}
\end{array}\right\}_{i}^{R} \\
& \left\{\begin{array}{l}
\Delta x \\
\Delta y
\end{array}\right\}_{i+1}^{L}=\left\{\begin{array}{l}
\Delta x \\
\Delta y
\end{array}\right\}_{i}^{R}+L_{i}\left\{\begin{array}{l}
\Delta \alpha_{x} \\
\Delta \alpha_{y}
\end{array}\right\}_{i}^{R}+\gamma_{2}\left\{\begin{array}{l}
\Delta M_{x} \\
\Delta M_{y}
\end{array}\right\}_{i}^{R}+\gamma_{3}\left\{\begin{array}{l}
\Delta Q_{x} \\
\Delta Q_{y}
\end{array}\right\}_{i}^{R}
\end{aligned}
$$$$
\left\{\begin{array}{l}
\Delta \alpha_{x} \\
\Delta \alpha_{y}
\end{array}\right\}_{i+1}^{L}=\left\{\begin{array}{l}
\Delta \alpha_{x} \\
\Delta \alpha_{y}
\end{array}\right\}_{i}^{R}+\gamma_{1}\left\{\begin{array}{l}
\Delta M_{x} \\
\Delta M_{y}
\end{array}\right\}_{i}^{R}+\gamma_{2}\left\{\begin{array}{l}
\Delta Q_{x} \\
\Delta Q_{y}
\end{array}\right\}_{i}^{R}
$$

\section{2) The expressions of torsional vibration}

\section{(1) The rigid disk}

The torsion moments of rigid disk are composed of the inertial moment, resisting moment, differential torsion moment between the left cross section and the right and the external moment. The increment equation of torsion moment is found as

$$
\Delta T_{i}^{R}=\Delta T_{i}^{L}+C_{1} \cdot \Delta \phi+A_{51} \Delta x+A_{52} \Delta y+C_{2}
$$

The increment equation of torsional angle relation between the left cross section and the right is:

$$
\Delta \phi_{i}^{R}=\Delta \phi_{i}^{L}
$$

\section{(2) The elastic shaft}

The increment equations of the elastic shaft can be expressed as:

$$
\left\{\begin{array}{l}
\Delta T_{i+1}^{L}=\Delta T_{i}^{R} \\
\Delta \phi_{i+1}^{L}=\Delta \phi_{i}^{R}+\frac{\Delta T_{i}^{R}}{K_{t}}
\end{array}\right.
$$

\section{3) Overall increment expressions of the coupled vibra-} tions

Assuming that the increment of moment vector in each section of the rotor is $f=\left[\Delta Q_{x}, \Delta Q_{y}, \Delta M_{x}, \Delta M_{y}, \Delta T\right]$ and displacement vector increment is $e=[\Delta x, \Delta y \mathbf{f} \Delta \mathbf{f} \neg \neg \mathbf{f} \boldsymbol{\beta} \rightarrow \Delta \varphi]$, so the increment equations of rigid disk and elastic shaft can be written in matrix form. The rigid disk and elastic shaft can be taken as an unit, and its transfer matrix is:

$$
\left\{\begin{array}{l}
f \\
e
\end{array}\right\}_{i+1}^{L}=\left[\begin{array}{ll}
U_{11} & U_{12} \\
U_{21} & U_{22}
\end{array}\right]\left\{\begin{array}{l}
f \\
e
\end{array}\right\}_{i}^{L}+\left\{\begin{array}{l}
F_{f} \\
F_{e}
\end{array}\right\}
$$

\section{Application of Riccati for Shaft Response}

The equation(12) can been obtained as

$$
\left\{\begin{array}{l}
f_{i+1}^{L}=U_{11} f_{i}^{L}+U_{12, i} \cdot e_{i}^{L}+F_{f, i} \\
e_{i+1}^{L}=U_{21} f_{i}^{L}+U_{22, i} \cdot e_{i}^{L}+F_{e, i}
\end{array}\right.
$$

Riccati expression is as follows:

$$
f_{i}=S_{i} e_{i}+P_{i}
$$

Then the recursive formulas of $S_{i}, P_{i}$ and $e_{i}$ can be obtained:

$$
\begin{aligned}
& S_{i+1}=\left[U_{11} \cdot S+U_{12}\right] \cdot\left[U_{21} S+U_{22}\right]^{-1} \\
& P_{i+1}=\left[U_{11} \cdot P+F_{f}\right]_{i}-S_{i+1}\left[U_{21} \cdot P+F_{e}\right] \\
& e_{i}=\left[U_{21} \cdot S+U_{22}\right]^{-1} \cdot e_{i+1}-\left[U_{21} \cdot S+U_{22}\right]^{-1}\left[U_{21} \cdot P+F_{e}\right]
\end{aligned}
$$

According to the boundary conditions, the methods of Riccati and Newmark- $\beta$, the displacement, velocity and acceleration of node at each time can be achieved.

\section{NUMERICAL EXAMPLES}

Taken a turbo-generator unit as example, the rotor structure is shown in Fig. 1. The unit is composed of high-pressure rotor, intermediate -pressure rotor, lowpressure rotor and generator rotor. There are seven bearings which position is shown in Fig. 1, and the rubbing position is near to $5 \#$ tile.

\section{A. Rotating Speed is Lower than the First Inherent Frequency}

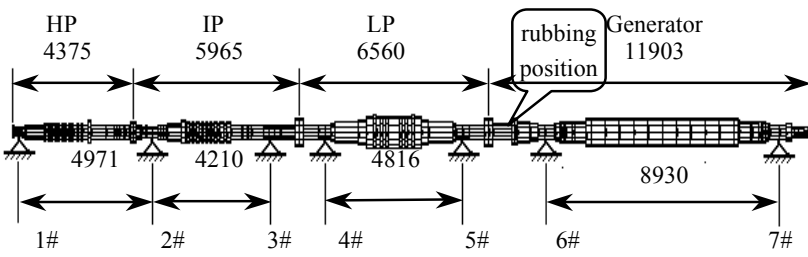

Figure 1 The rotor structure of turbo-generator unit (unit:mm)

Fig. 2 shows the time curves and orbit maps of bending vibration with and without rubbing when rotating speed is $14 \mathrm{~Hz}$ which is lower than the first inherent frequency. In the figure, red curves represent that with rubbing, blue curves are to without rubbing. It is obvious that bending vibration amplitude of each tile increases rapidly after rub-impact happens. The sensitive to rubbing position is different for increased vibration amplitude of each tile. The increased amplitude of $3 \#$ tile and $5 \#$ tile are more sensitive than that of $1 \#$ tile. It is means that the shaft segment is more near to the rubbing position, the increased vibration amplitude is more obvious. The main frequency of bending vibration of each tile is working frequency when there is no rubbing fault. And the orbit map of each tile is circle or ellipse. After rubbing fault happens, the bending vibration amplitude of each tile increases very quickly, axis orbit change is relatively complex. After about 2-3 cycles, the vibration amplitude tends to be stable.

Fig. 3 shows the time curves of torsional vibration with and without rubbing when rotating speed is low than the first inherent frequency. From the figure, we can see that torsional vibration amplitude of each tile increases to a 

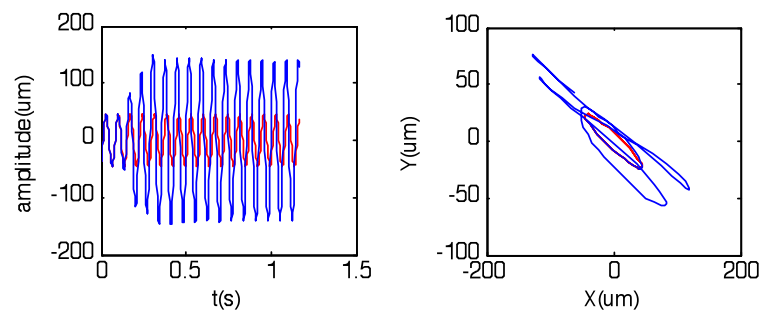

(a) 1 \# tile
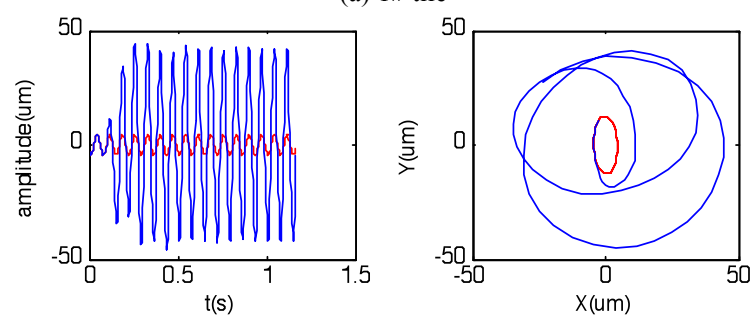

(b) $3 \#$ tile
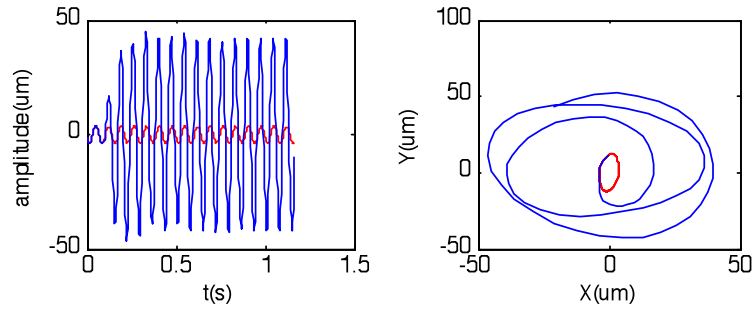

(c) $5 \#$ tile

Figure 2 The time curves(left column) and orbit maps(right column) of bending vibration with and without rubbing when rotating speed is 14 $\mathrm{Hz}$

certain extent after rub-impact happens. The sensitive to rubbing position is different for increased vibration amplitude of each tile. The increased amplitude of $3 \#$ tile and $5 \#$ tile are bigger than that of $1 \#$ tile.

The comprehensive comparison of the above analysis results is shown in Fig. 4. Fig.4(a) describes the peak value curves of bending vibration of each shaft segment with and without rubbing when rotating speed is low than the first inherent frequency. It is obvious that the vibration amplitude of each shaft segment increases after rubimpact happens. The sensitive to rubbing position is different for increased vibration amplitude of each shaft segment. The sensitives of 50-80 shaft segments that are near the rubbing position are the most high. Fig.4(b) describes the peak value curves of torsional vibration of each shaft segment with and without rubbing. Torsional vibration amplitude of each shaft segment increases to a certain extent after rub-impact happens. The shaft segment is more near to the generator side, the increased vibration amplitude is more obvious.

\section{B. Rotating Speed is Higher than the First Inherent Frequency}

Fig. 5 shows the time curves and orbit maps of bending vibration with and without rubbing when rotating speed is $50 \mathrm{~Hz}$ which is high than the first inherent frequency. After rubbing fault happens, the vibration amplitude of each tile increases slightly. In contrast to rotating speed low than the first inherent frequency, the increasedvibration amplitude is litter. Before rubbing fault happens, the main frequency of bending vibration of each tile is
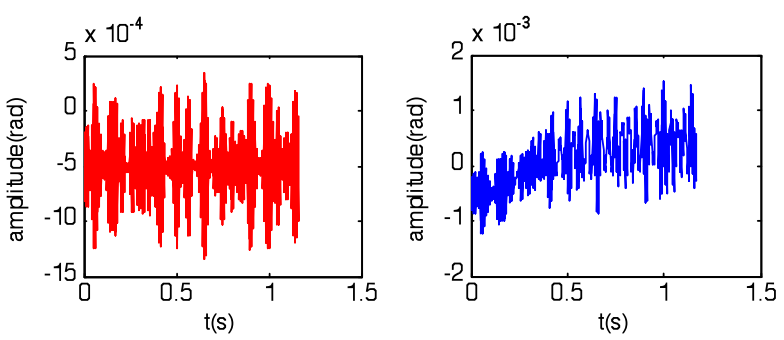

(a) 1 \# tile
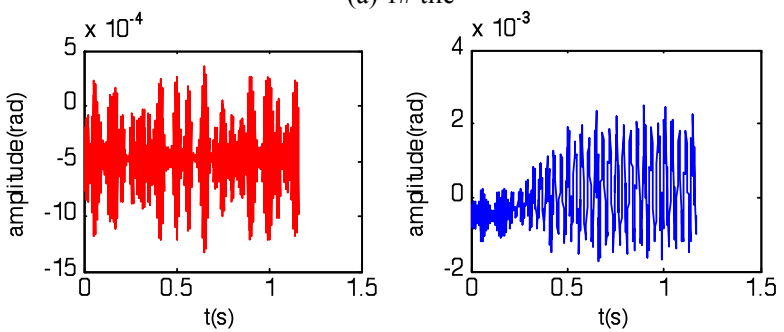

(b) $3 \#$ tile
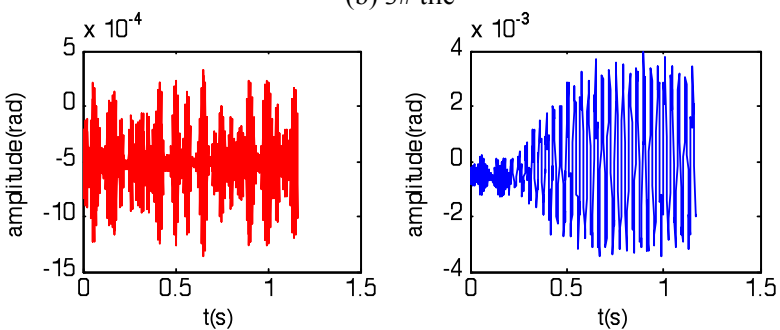

(c) $5 \#$ tile

Figure 3 The time curves of tosrional vibration with(right column) and without rubbing(left column) when rotating speed is $14 \mathrm{~Hz}$

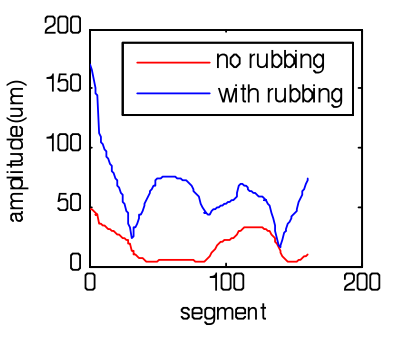

(a) bending vibration

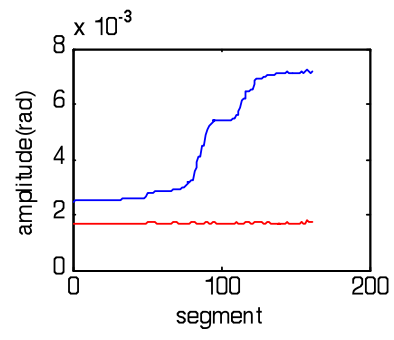

(b) torsional vibration
Figure 4 The peak value curves of bending and torsional vibrations with and without rubbing when rotating speed is $14 \mathrm{~Hz}$

working frequency. And the orbit map of each tile is circle or ellipse. After rubbing fault happens, the bending vibration amplitude of each tile increases slightly. After about 2-3 cycles, the vibration amplitude tends to be stable.

Fig. 6 shows the time curves of tosrional vibration with and without rubbing when rotating speed is high than the first inherent frequency. According to the curves, we can find that torsional vibration amplitude of each tile increases to a certain extent after rub-impact happens. The increased amplitude of $3 \#$ tile and 5\# tile are big than that of 1 \# tile.

The comprehensive comparison of the above analysis results is shown in Fig. 7. Fig. 7(a) describes the peak value curves of bending vibration of each shaft segment with and without rubbing when rotating speed is high than the first inherent frequency. It is obvious that the vibration amplitude of each shaft segment increases after rubimpact happens. Comparing with the situation that rotat- 

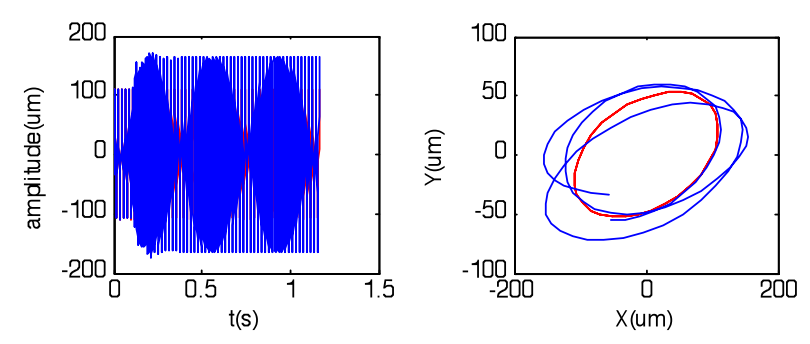

(a) 1 \# tile
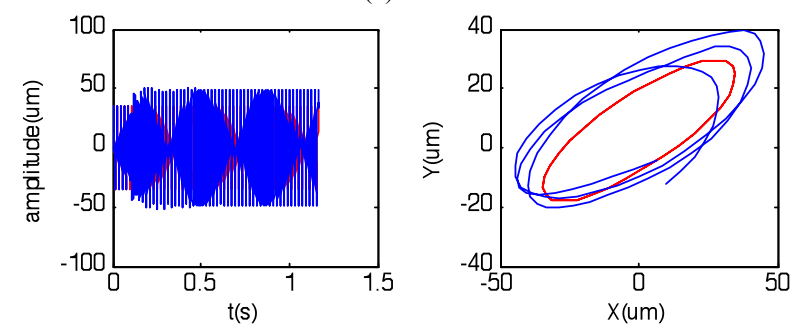

(b) $5 \#$ tile
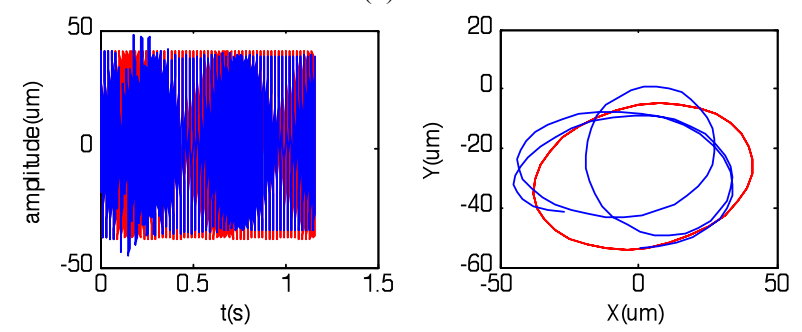

(c) $5 \#$ tile

Figure 5 The time curves(left column) and orbit maps(right column) of bending vibration with and without rubbing when rotating speed is $50 \mathrm{~Hz}$

ing speed is low than the first inherent frequency, the increased vibration amplitude becomes much smaller. Fig. 4(b) shows the peak value curves of torsional vibration of each shaft segment with and without rubbing. Torsional vibration amplitude of each shaft segment increases to a certain extent after rub-impact happens. The shaft segment is more near to the generator side, the increased vibration amplitude is more obvious. The increased vibration amplitude is small than the situation that rotating speed is low than the first inherent frequency.

To sum up, the influence of rotating speed on vibration amplitude is obvious. When the speed is lower than the first order inherent frequency, rubbing will cause bending and torsional vibration amplitudes of each axis segment increase largely; When the speed is higher than the first order inherent frequency, vibration amplitudes changed by rubbing only slightly increase. The reason is that rotor mass unbalance will increase when the speed is lower than the first order inherent frequency. So the vibration amplitudes increase. When the speed is higher than the first order inherent frequency, rubbing will make the rotor mass unbalance change litter, thereby vibration amplitude will change slightly.

\section{CONCLUSIONS}

The rub-impact phenomenon is one of the main troubles in turbo-generator unit and severely affects the natural operation of the machines. The increment transfer matrix method is used to analyze the dynamic response of the coupled bending and torsional vibrations of turbo-
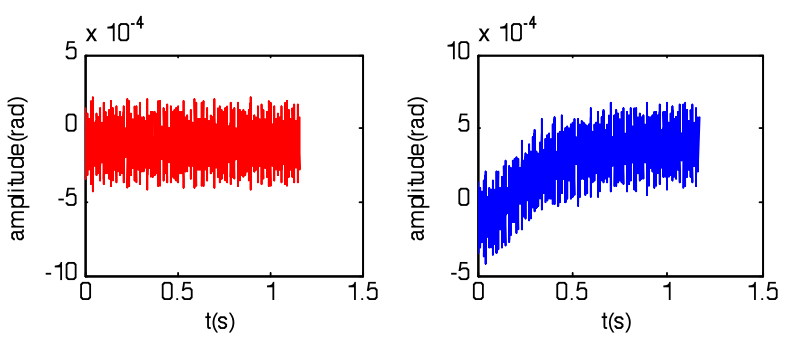

(a) $1 \#$ tile
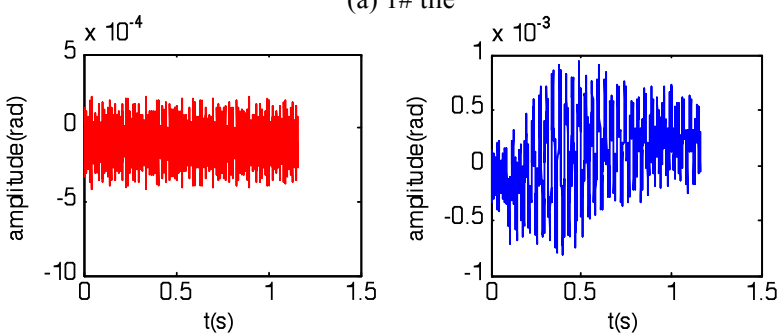

(b) $3 \#$ tile
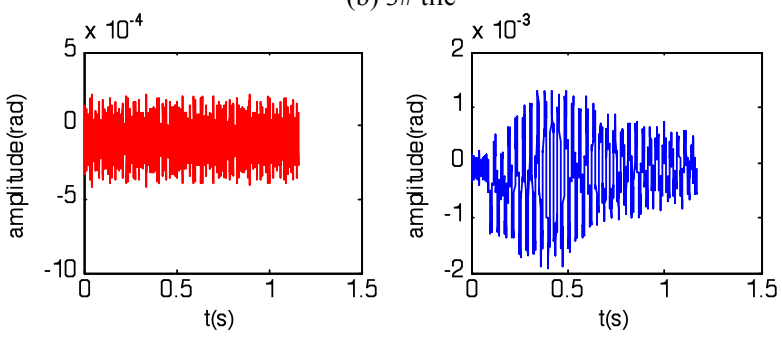

(c) $5 \#$ tile

Figure 6 The time curves of tosrional vibration with(right column) and without rubbing(left column) when rotating speed is $50 \mathrm{~Hz}$

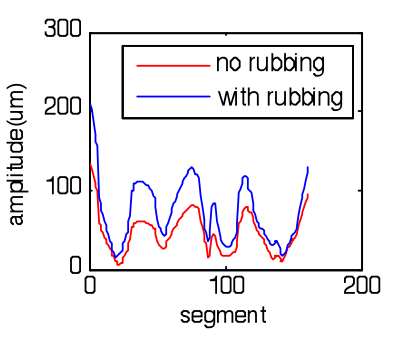

(a) bending vibration

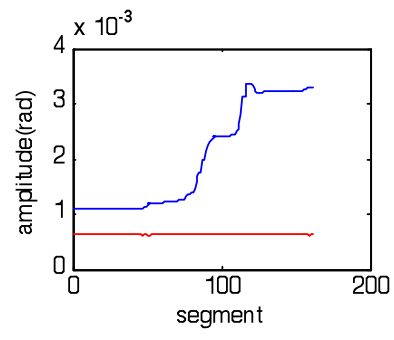

(b) torsional vibration
Figure 7 The peak value curves of bending and torsional vibrations with and without rubbing when rotating speed is $50 \mathrm{~Hz}$

generator shafts with rub-impact in this work. According to the research results, we can find that the influence ofrotating speed on vibration amplitude is evident. When the speed is lower than the first order inherent frequency, the bending and torsional vibration amplitudes of each shaft segment will increase largely; When the speed is higher than the first order inherent frequency, the vibration amplitudes changed by rubbing only slightly increase. And the shaft segment is more near to the rubbing position, the increased vibration amplitude is more obvious.

\section{ACKNOWLEDGMENT}

The authors are grateful for the financial support from National Science Foundation of China (Grant No. 50905058 and No.51075145), Beijing Natural Science Foundation (Grant No. 3132015) and the Fundamental Research Funds for the Central Universities (Grant No. 12ZX01). 


\section{REFERENCES}

[1] C. B. He, Y. J. Gu and C. Xing, "Coupled Flexural and Torsional Vibrations Analysis of Turbine Generator Shaft Systems Caused by Short Circuit Fault", Proceedings of the CSEE, Vol. 30, No. 32, pp.84-90, 2010.

[2] I. Gustavsson, J. Zackrisson, and K. Nilsson, “A flexible electronics laboratory with local and remote workbenches in a grid", International Journal of Online Engineering, vol 4, no 2, pp: 12-16, 2009

[3] Z. W. Yuan, F. L. Chu and Y. L. Lin, "External and internal coupling effects of rotor's bending and torsional vibrations under unbalances", Journal of Sound and Vibration, Vol. 299, No.1, pp.339-347, 2007. http://dx.doi.org/10.1016/i.jsv.2006. $\underline{06.054}$

[4] Li CF, Li H and Ma H, "Bifurcation and stability of the flexible rotor-bearing system with rub-impact by a continuum model", Journal of Mechanical Engineering, Vol.46, No.11, pp.107-113, 2010. http://dx.doi.org/10.3901/JME.2010.11.107

[5] S. C. Hsieh, J. H. Chen and A. C. Lee, "A modified transfer matrix method for the coupled lateral and torsional vibrations of asymmetric rotor-bearing systems", Journal of Sound and Vibration, Vol.312 , pp.563-571, 2008. http://dx.doi.org/10.1016/ j.jsv.2008.01.006

[6] Roques, S., Legrand, M., Cartraud, P., Etc, "Modeling of A Rotor Speed Transient Response With Radial Rubbing", Journal of Sound And Vibration, Vol. 329, No.5, pp. 527-546, 2010. http://dx.doi.org/10.1016/j.jsv.2009.09.016

[7] M. Kozek, C. Bilik, and C. Benatzky, "A PC-based flexible solution for virtual instrumentation of a multi-purpose test bed", International Journal of Online Engineering, vol 2, no 4, Spec. Iss, pp: 5-9, 2009

[8] T. H. Patel, Zuo MJ and ZhaoXM, "Nonlinear Lateral-Torsional Coupled Motion of A Rotor Contacting A Viscoelastically Suspended Stator", Nonlinear Dynamics, Vol.69, No.1-2, pp. 325339, 2012. http://dx.doi.org/10.1007/s11071-011-0267-0

[9] Jia JH and Hang TQ, "Effect of the Initial Deflection On Vibration Characteristics of the Rub-Impact Rotor System", Mathe- matical \& Computational Applications, Vol.15, No.5, pp. 768775, 2010.

[10] Ma, H, Yu T and Han QK, "Time-Frequency Features of Two Types of Coupled Rub-Impact Faults in Rotor Systems", Journal of Sound and Vibration, Vol.321, No.3-5, pp. 1109-1128, 2009. http://dx.doi.org/10.1016/j.jsv.2008.09.054

\section{AUTHORS}

He Chengbing received the $\mathrm{PhD}$ degree in thermal power engineering from the School of energy, power and mechanical engineering, north china electric power university in 2004 . He is currently an associate professor in north china electric power university. In addition to teaching power engineering courses ranging from steam turbine equipment to mechanics theory, his reserach interests include on-line monitoring and analyze of coupled bending and torsional vibrations, fault diagnose of thermal equipment in power plant, and state maintainance of thermal equipment, etc(hcbyy@126.com).

Yang Li received the master's degree in thermal power engineering from the School of energy, power and mechanical engineering, north china electric power university in 2003. She is currently a Senior Engineer in China Coal Research Institute. Her reserach interests are focus on vibration monitoring and analysis of rotate equipment and the clean utilization of coal, etc (yanglibb@sohu.com).

This article is an extended and modified version of a paper presented at the International Conference on Mechanical Engineering, Automation and Material Science (MEAMS2012), held 22-23 December 2012 , Wuhan, China. Received 14 February 2013. Published as resubmitted by the authors 25 March 2013. 